\title{
Energy savings through integration of the illumination natural and artificial, using a system of automatic dimming:Case study
}

\author{
D. Milone ${ }^{1, a}, S$. Pitruzzella ${ }^{2, b}$, V. Franzitta ${ }^{1, c}$, A.Viola $^{1, d}, M$. Trapanese ${ }^{1, e}$ \\ ${ }^{1}$ DEIM - Dipartimento Di Energia, Ingegneria Dell'informazione, E Modelli Matematici, \\ University of Palermo, Palermo 90128, Italy \\ ${ }^{2}$ Facoltà di Architettura Università degli Studi Palermo, Viale delle Scienze 14, \\ Palermo 90128, Italy
}
a daniele.milone@unipa.it, ${ }^{b}$ salvatore.pitruzzella@unipa.it, ${ }^{c}$ franzitta@dream.unipa.it, 'alessia.viola@unipa.it, ${ }^{\mathrm{e}}$ marco.trapanese@unipa.it

\begin{abstract}
Keywords: consumption; dimmer;Electrical energy consumption;dayligthing.
Abstract. The reduction of electrical energy consumption in buildings is a subject of great interest in the international scientific community. In buildings with a lot of available natural light, designed with large glazed surfaces, the artificial lighting system is often oversized and cannot be divided into segments to meet lighting demands during daylight hours.

This article presents an experimental study, conducted in a university lecture hall that has a glazed surface covering the whole wall at one end, which provides a level of internal illumination that is only sufficient for the area next to the window itself, even when the outside lighting conditions are very bright. It is therefore necessary to turn on the artificial lighting system.

The mathematical approach used in this paper has been successfully applied by the authors in other fields of science [1-2].

Using an automatic dimmer system, the calibration of which is based on experimental measurements, the lighting is arranged in such a way as to illuminate the most disadvantaged areas of the room, and then to extend itself gradually to the whole of the room, over the period of time that the lecture hall is in use.
\end{abstract}

\section{Introduction}

Rooms intended for teaching in a university faculty, even though they have large glazed surfaces, are often used by the users (students and teachers) with artificial lighting for the entire day, even when there is a high level of daylight illuminance.

This is the case with the lecture halls of the Faculty of Architecture of Palermo, which, as can be deduced from figure 1 below, are characterised by a large glazed surface that extends across the entire area of the wall.

In spite of this, the availability of daylight is very low in the area opposite the glazed surface, as can be deduced from figure 2 .

In particular, in the figures mentioned above, which represent the state of the Sky Component, simulated with Ecotect v5.50 software [3], it can be deduced that starting from 4 meters away from the windows, the SC descends below 5\% down to very low values in the area occupied by the lecturer's desk $(0.75 \%)$.

This involves the turning on of the artificial lighting installation characterised by the simultaneous turning on of all the lighting units.

Following the guideline aimed at minimizing energy consumption, an evaluation was considered of the savings that could be obtained with a dimmer system that allows the graduated turning on of each lighting unit, depending on the amount of illuminance required for the visual tasks carried out in the room, (300 lux) with the actual availability of daylight [4].

This involves the turning on of the artificial lighting installation characterised by the simultaneous turning on of all the lighting units. 
Following the guideline aimed at minimizing energy consumption, an evaluation was considered of the savings that could be obtained with a dimmer system that allows the graduated turning on of each lighting unit, depending on the amount of illuminance required for the visual tasks carried out in the room, (300 lux) with the actual availability of daylight [4].

Figure 1. Plan and picture of the room that is the subject of the experiment
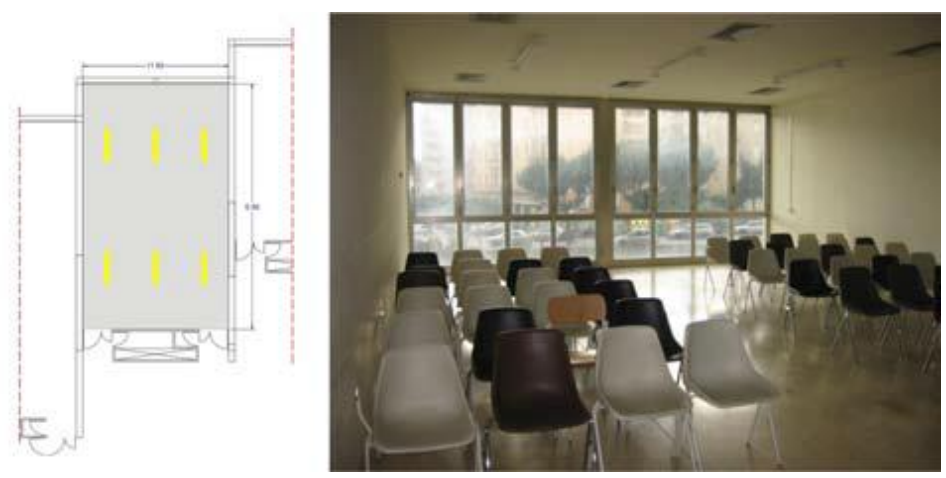

Figure 2. (a)Mapping of the Sky Component values; (b)Variation of the sky component values along the longitudinal section of the room

(a)

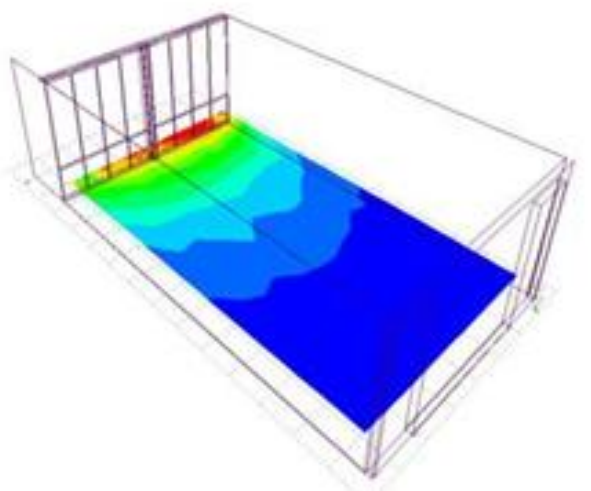

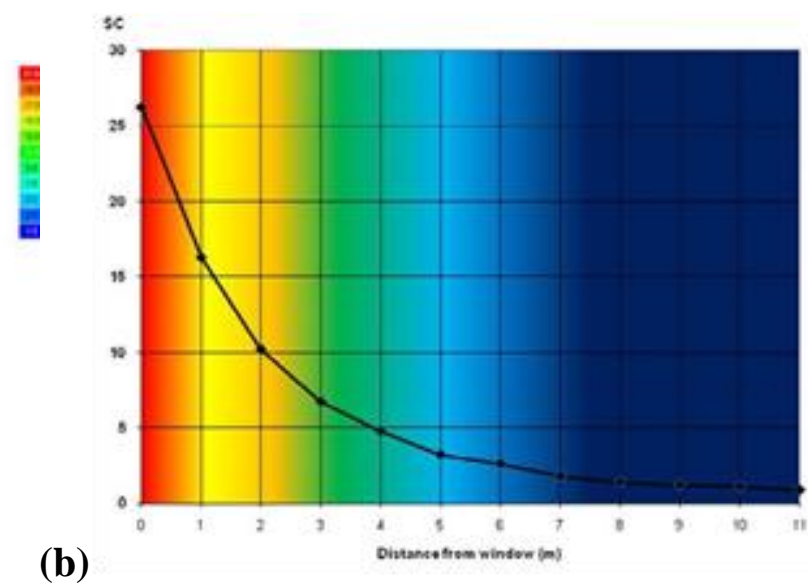

(b)

\section{Description of the environment}

The room used is already shown in figure 1 , size $11.2 \mathrm{~m} \times 7 \mathrm{~m}$, and it is equipped with a lighting installation made up of 6 lighting units, each with 258 Watt "mastercolour" [5] fluorescent tubes with a total power of 696 Watts. Natural light comes from a glazed surface that is $6.8 \mathrm{~m} \times 2.8 \mathrm{~m}$ including the aluminiumframe which covers $12 \%$ of it. The internal surfaces are characterised by a reflection coefficient that can be defined as "high". The lighting units and the surface of the walls have a high maintenance coefficient [6].

As has already been said, the lighting units all turn on simultaneously

Methodology. In the room used for this experiment the electricity supply system has been substituted, and consequently each lighting unit has been equipped with its own electric line and its own electronic control system (dimmer) [7].

All the lines come together at a main circuit breaker on which a network analyser capable of continually evaluating and acquiring the daily, weekly and monthly consumption of electricity has been placed.

The same measuring system has been placed in the room on the floor immediately above, and therefore with the same geometric characteristics, the same installations and the same exposure to sunlight, in order to highlight and compare the consumption.

The results obtained in percentage terms have been compared with the ones estimated using the photoelectric dimming function of the Ecotect software of Square One. 
This function, which uses daylight analysis for the average value of the daylight factor inside the room and for the illuminance required, shows the percentage working year lighting off in a graph represented in figure 3.

Figure 3. Percentuage working year lighting off

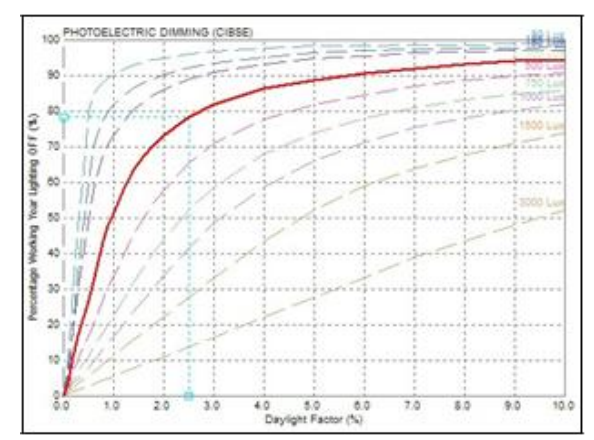

The estimated use of this diagram has allowed the identification of a saving of about $30 \%$ with an electronic dimmer system [8], for the case being examined in which the average Daylight factor is $2.5 \%$, with a predicted illuminance on the working surfaces of 300 lux.

These estimates, together with what has been written in scientific studies in this field [9], [10], have reassured the authors, as well as the financial backers, about the economic convenience of the project.

The electronic dimmer system

For the planning of the functioning of the installation, a system with a fuzzy logic [11] processor was used, with which it is possible to turn the installation on or off using information about the presence/absence of people in the room [12] With this system it is possible to overcome the limitations of binary logic, using vague overall identifiers, that is, information with a degree of ambiguity, uncertainty or imprecision, which comes from a complex system, such as a system for acquiring numerous pieces of information, like physical size and the environmental circumstances correlated to it.

The fuzzy system, quoting the concept of set theory, is capable of:

- Establishing membership classifications;

- Establishing membership functions;

- Establishing rules of connection between all the information that is attained through the IFTHEN criterion;

- Processing the input information to get the output information.

In particular, information obtained from a light sensor about the amount of natural light, brings about the modulation of supply voltage of the lamps (dimming), through a transformer; this allows the exact amount of artificial light necessary to be used to maintain the lighting levels required by the UNI (Italian National Standards Institute) - En 12464.

To simplify the dimming process an illuminance range of between 200 and 350 lux has been fixed. It is divided into ten classifications, and a dimming voltage corresponds to each of the classifications.

As has already been pointed out, a sensor is able to disconnect the functioning of the circuit even in the presence of low illuminance values.

To simplify the system, the input information, containing information about the actual immediate availability of natural light, is correlated to the patterns of the mark of the sun and the daylight factor values.

These patterns have been obtained through dynamic simulations and validated with instrumental measurements in the field. Consequently the system is programmed in such a way that the lights are 
turned on in a progressive way, starting from the right hand side of the area opposite the glazed surface [13], [14].

These connections have been programmed for 11 possible classification combinations. Some possible combinations are quoted in table 1.

The dimming supplier is piloted by a continuous voltage according to an inverse relationship between the pilot tension and the illuminance produced by the lamps.

Observing table 2 below, this means that the maximum lighting of the lamps corresponds to a voltage of 2.0 Volts, and the turning off of the lamps corresponds to 9.2 Volts. The system, through transformers, controls 3 input variables (illuminance on the work surfaces, occupation of the room and delay in turning off), and an output variable (voltage regulation); intermediate functions, whose combination allows the modular functioning of the lighting installation, are assigned to the input variables [15-17].

Table 1. Somepossiblecombinationsofcontrolsignals

\begin{tabular}{|lll|}
\hline IF & \multicolumn{1}{|c|}{ AND } & THEN \\
\hline LUX verylow & Presence yes & Dim 00 (Full on) \\
\hline Lux low & Presence yes & Dim 02 \\
\hline Lux little & Presence yes & Dim 04 \\
\hline Lux midle & Presence yes & Dim 14 \\
\hline Lux very high & Presence yes & Dim 20 (Total OFF) \\
\hline LUX verylow & Presence NO & Dim 20 (Total OFF) \\
\hline Lux midle & Presence NO & Dim 20 (Total OFF) \\
\hline
\end{tabular}

Table 2. Controlclassificationsofdimming

\begin{tabular}{|ccc|}
\hline Class & E (lux) & Volt \\
\hline 1 & $\mathbf{1 0 0 - 1 2 0}$ & $\mathbf{2 . 0}$ \\
\hline 2 & $\mathbf{1 2 1 - 1 4 0}$ & $\mathbf{2 . 8}$ \\
\hline 3 & $\mathbf{1 4 1 - 1 6 0}$ & $\mathbf{3 . 6}$ \\
\hline 4 & $\mathbf{1 6 1 - 1 8 0}$ & $\mathbf{4 . 4}$ \\
\hline 5 & $\mathbf{1 8 1 - 2 0 0}$ & $\mathbf{5 . 2}$ \\
\hline 6 & $\mathbf{2 0 1 - 2 2 0}$ & $\mathbf{6 . 0}$ \\
\hline 7 & $221-240$ & $\mathbf{6 . 8}$ \\
\hline 8 & $\mathbf{2 4 1 - 2 6 0}$ & $\mathbf{7 . 6}$ \\
\hline 9 & $\mathbf{2 6 1 - 2 8 0}$ & $\mathbf{8 . 4}$ \\
\hline
\end{tabular}

Experimental results.The results obtained are represented in table 3 and subsequently in the graph in figure 4.It has been decided to show the results as monthly consumptions, to simplify the conclusions.

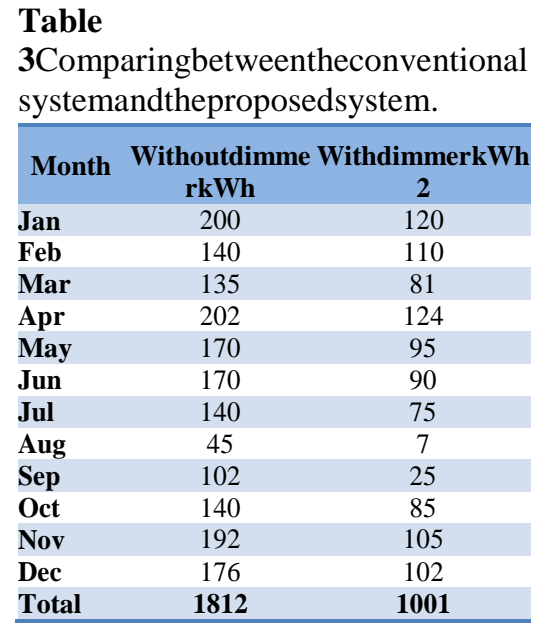

Figure 4. Annual progressofconsumption.

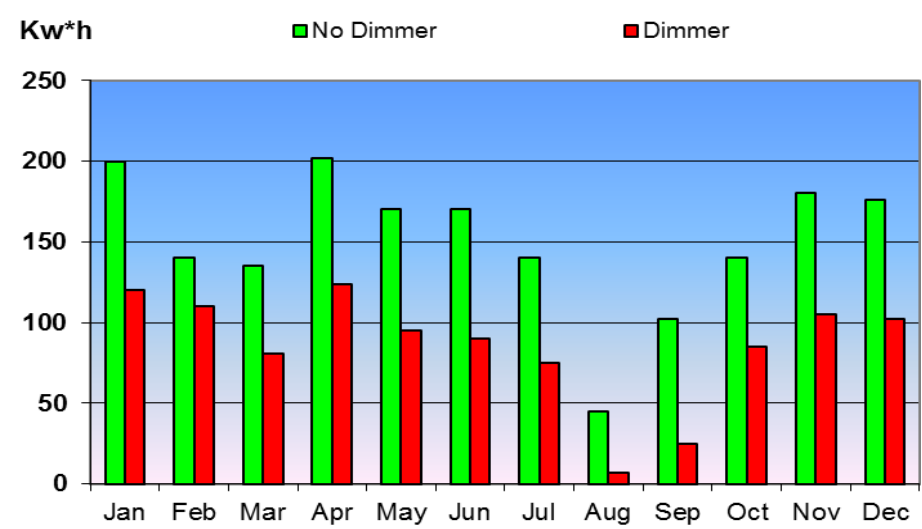

The total consumption in the year under consideration (2007) went down from $1812 \mathrm{kWh}$ to $1001 \mathrm{kWh}$ with a total saving of $811 \mathrm{kWh}$, equivalent to $44 \%$.

In order to highlight the behaviour of the system better, figures 5 (a) (b)and (c) show diagrams of specific uses calculated at intervals of 20 minutes, from three significant days of the year - the 7th February, the 15th June and the 10th December.

From these diagrams it can be deduced that at certain times of day, more precisely between 1.20 $\mathrm{pm}$ and $2.40 \mathrm{pm}$, and between $6.40 \mathrm{pm}$ and $7.20 \mathrm{pm}$, the installation is completely switched off (occupation sensor of the room - off), and that the power supplied adapts instantly to the requirements for visual comfort as the amount of natural light varies 
Figure 5. (a) Consumption on the 7th February; (b)Consumption on the 15th June; (c)Consumption on the 10th December
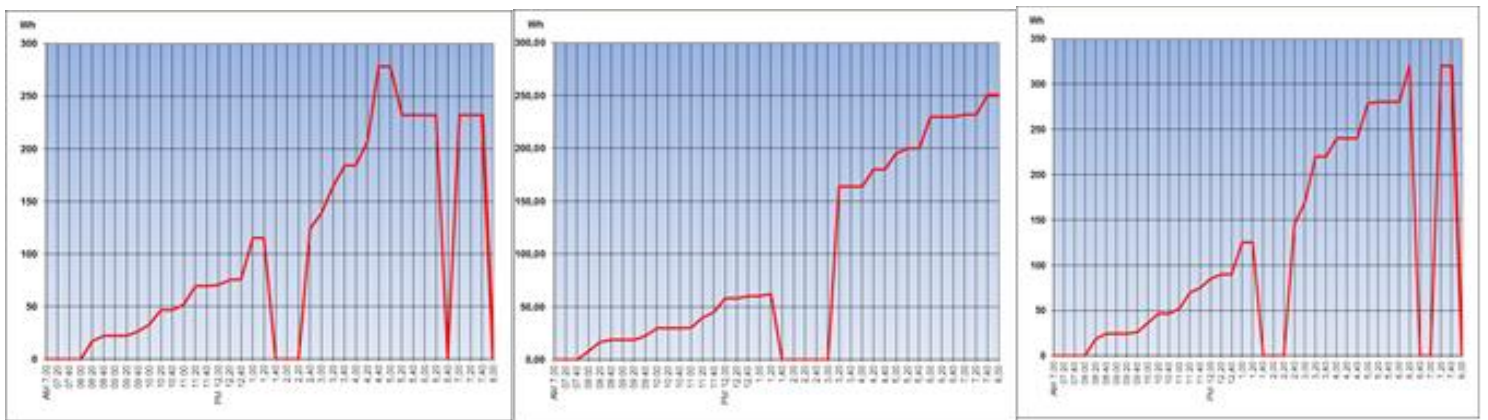

Conclusions .The results obtained demonstrate the energy efficiency obtained with a domotic regulation system of the luminous flux.[18-19].

Compared with the theoretical savings obtainable from the simulations, much better results have been obtained, above all, because management using Fuzzy Logic allows the installation to be switched off in the absence of users. In fact, on 250 sample days, between $1.30 \mathrm{pm}$ and $3.00 \mathrm{pm}$, 100 occurrences of turning off because of an absence of occupants in the room were identified, and another complete turning off of the lighting was noticed in the months of December, after $6.00 \mathrm{pm}$, which coincided with the end of lessons.

Finally, in line with the previous verifications already described about the hourly availability of natural light, the regulation system allowed not only the turning on of one or more lamps, but also the individual regulation of the flux and consequently the necessary electric power.

\section{References}

[1] Trapanese M.; Franzitta V., Viola A. The Jiles Atherton Model for Description Of Hysteresis in Lithium Battery. Conference Proceedings - IEEE Applied Power Electronics Conference and Exposition - APEC 2013- Long Beach,(CA), March 2013-978-1-4673-4355-8, pp 2773-2775.

[2] Sorrentino, G., Ferrante, P., Franzitta, V., Gennusa, M.L., Nicolosi, S., Scaccianoce, G., Viola, A. Generation of a test reference year (TRY): An application to the town of Palermo, Advanced Materials Research 622, (2013), pp 1835-1840.

[3] http://squ1.com.

[4] UNI EN 12464-1:2004, riguardante "Light and lighting - Lighting of work places - Part 1: Indoor work places"

[5] http://www.lighting.philips.com/

[6] Moncada Lo Giudice G., de Lieto Vollaro A., Illuminotecnica, Milano 1999

[7] Floyd, D.B., Parker, D. S., "Field Commissioning of a Daylight-Dimming Lighting System", Proceedings of the 3rd European Conference on Energy-Efficient Lighting - Right Light 3, Newcastle, England, 1995

[8] Benton, C., Fountain, M., Selkowitz, S., Jewell, J. "Control System Performance in a ModernDaylighted Office Building".Proceedings of the 22nd session of the CIE, vol. 1, Melbourne, 1991.pp.31-24. 
[9] Brekke, B., Hansen, E. H., "Energy Saving in Lighting Installations by Utilizing Daylight", CADDET Energy Efficiency, 1997

[10] Sorcar, Praefulla C.: Energy Saving Light Systems. Van Nostrand Reinhold, New York 1982.

[11]Zimmermann H., Fuzzy Set Theory and its Applications (2001) Daylight in building.

[12] Sorcar, Parfulla C.: Rapid Lighting Design and Cost Estimating. McGraw-Hill, New York 1979

[13] R. Ganslandt, H. Hofmann, Handbook of Lighting Design, Braunschweig/Wiesbade 1992

[14] Milone A., Milone D., Pitruzzella S., "An simulation of daylight levels for the determination of visual comfort in large spaces". Proceedings of $10^{\circ}$ International Building Performance Simulation Association Conference and Exhibition.BuldingSimulation 2007. Pagg. 1232-1237; 3-6 semptember 2007. Tsinghua. Cina.

[15] Philips: Lighting Manual. 3rd Edition. Philips, Eindhoven 1988

[16] Majoros A.T., "Basic daylight for architetct” Budapest 1998.

[17] Galatioto A, Milone D., Pitruzzella S, Scaccianoce G., Regional policies for sustainability in the Mediterranean countries: the role of a proper HVAC system maintenance in museums. Applied Mechanics and Materials Vols. 316-317 (2013) pp 1147-1151 doi:10.4028/www.scientific.net/AMM.316-317.1147.

[18]Franzitta, V., Viola A., Trapanese M.; Description of hysteresis in Lithium battery by classical Preisach model, Advanced Materials Research Vols. 622-623 (2013) pp 1099-1103.

[19] Ciulla G., Franzitta V.; Lo Brano V., Viola A., Trapanese M., Mini Wind Plant to Power Telecommunication Systems: a Case Study in Sicily, Advanced Materials Research Vols. 622-623 (2013) pp 1078-1083. 